\title{
Finite element analysis of cementless femoral stems based on mid- and long-term radiological evaluation
}

Kanehiro Matsuyama ${ }^{1 \dagger}$, Yasuhiro Ishidou ${ }^{*^{*}+}$, Yong-Ming Guo ${ }^{2}$, Hironori Kakoi ${ }^{3}$, Takao Setoguchi ${ }^{4}$, Satoshi Nagano ${ }^{3}$, Ichiro Kawamura', Shingo Maeda' and Setsuro Komiya ${ }^{1,3,4}$

\begin{abstract}
Background: Femoral bone remodeling in response to stress shielding induces periprosthetic bone loss. Computerized finite element analysis (FEA) is employed to demonstrate differences in initial stress distribution. However, FEA is often performed without considering the precise sites at which the stem was fixed. We determined whether FEA reflects mid-term radiological examination exactly as predicted following long-term stress shielding.

Methods: Femur-stem fixation sites were evaluated radiologically according to the location of spot welds in two anatomical cementless stem designs. Based on mid-term radiological results, four femur-stem bonding site conditions were defined as: (Condition A) no bonding; (Condition B) bonding within the $10 \mathrm{~mm}$ area proximal to the distal border of the porous area; (Condition C) bonding of the entire porous area; and (Condition D) bonding of the entire femoral stem, prior to conducting FEA analysis. Furthermore, we radiographically evaluated mid- and long-term stress shielding, and measured bone mineral density of the femur 10 years after total hip arthroplasty.

Results: Spot welds appeared frequently around the border between the porous and smooth areas. FEA showed that, based on mid-term radiological evaluation, von Mises stress was reduced in condition B in the area proximal to the femur-stem bonding sites for both stem designs compared with condition A (no bonding). Conversely, von Mises stress at all areas of the femur-stem bonding sites in conditions $C$ and $D$ was higher than that in condition $A$. With respect to stress shielding progression, there was no significant difference between the two types of stem designs. However, stress shielding progressed and was significantly higher in the presence of spot welds $(p=0.001)$. In both stem designs, bone mineral density in zone VII was significantly lower than that in the contralateral hips.
\end{abstract}

Conclusions: These results indicate that FEA based on mid-term radiological evaluation may be helpful to predict the influence of long-term stress shielding more precisely.

Keywords: Finite element analysis (FEA), Stress shielding, Cementless stem, Total hip arthroplasty (THA)

\section{Background}

Advances in stem surface processing technologies have led to improved fixation of cementless femoral stems following total hip arthroplasty (THA), resulting in better long-term outcomes [1-4]. A variety of cementless femoral stems are widely used, with excellent long-term outcomes [5]. Conversely, improvements in cementless

\footnotetext{
*Correspondence: ishidou@m2.kufm.kagoshima-u.ac.jp

${ }^{\dagger}$ Equal contributors

'Department of Medical Joint Materials, Graduate School of Medical and Dental Science, Kagoshima University, 8-35-1 Sakuragaoka, Kagoshima 890-8520, Japan

Full list of author information is available at the end of the article
}

implant fixation can result in stress shielding issues in the proximal femur. Femoral bone remodeling in response to stress shielding, incurred by altering the implant design, can induce periprosthetic bone loss $[4,6$, 7]. Bone loss due to stress shielding is a key factor in aseptic loosening, subsidence and periprosthetic femoral fracture, making revision surgery difficult [8-10].

Computerized finite element analysis (FEA) is widely employed to demonstrate differences in initial stress distribution diversified by stem design, and to estimate stress shielding depending on periprosthetic bone remodeling [11-14]. However, FEA is often performed 
with the stem not bonded onto the femur, or with it completely bonded, without considering the sites at which the stem is fixed. In many studies, FEA was performed when the whole porous coated surface was bonded to the femur [15-18]. Broeke et al. reported that FEA in the fully bonded condition with proximal hydroxyapatite coating could not completely match the clinical findings [15]. Osseointegration between the implant and bone is not achieved immediately after THA and does not occur over the whole porous coated surface [16]. Scannell et al. describe that osseointegration occurs over a period of time and is determined by numerous factors [17]. Therefore, simulations should take this osseointegration process into account. These findings show that FEA prediction of long-term outcomes has not been achieved yet. Clinical data to help modulate the FEA conditions to make more accurate estimates of long-term clinical results are therefore needed.

Radiographic visuals, such as spot welds, predict fixation of cementless stems to bone by osseointegration [19]. FEA carried out without considering these in vivo bone reactive sites may not accurately predict the long-term outcome. Few reports have examined the influence of stem and femur bonding condition on FEA performance.

We radiologically evaluated femur-stem fixation sites according to the location of spot welds in two cementless stem designs. Based on mid-term radiological results, we defined four femur-stem bonding conditions and performed FEA. Furthermore, we radiographically evaluated mid- and long-term stress shielding, and measured bone mineral density (BMD) of the femur via dual energy X-ray absorptiometry (DEXA) 10 years after THA. We determined whether FEA exactly reflected mid-term radiological examination to predict long-term stress shielding.

\section{Methods}

\section{Subjects}

We conducted a retrospective study in 41 patients (48 hips) who underwent THA and bipolar hemiarthroplasty with either Citation (Stryker, Tokyo, Japan) (Fig. 1a) or Spongiosa (Zimmer, Warsaw, IN, USA) (Fig. 1b) prostheses from 1999 to 2006. From these, a total of 31 patients (35 hips) were followed-up for more than 5 years postoperatively. The Citation prosthesis was used in 16 patients (16 hips: 4 male hips and 12 female hips; Group C) and the Spongiosa was used in 15 patients (19 hips: 7 male hips and 12 female hips; Group S). The mean age at surgery was 54.8 years (range, 34-76 years) in Group $\mathrm{C}$ and 58.4 years (range, 27-74 years) in Group S. In Group $\mathrm{C}$, the preoperative diagnosis was osteoarthritis (OA) in 8 hips, osteonecrosis in 5 hips, rheumatoid arthritis in 2 hips, and femoral neck fracture in one hip. In

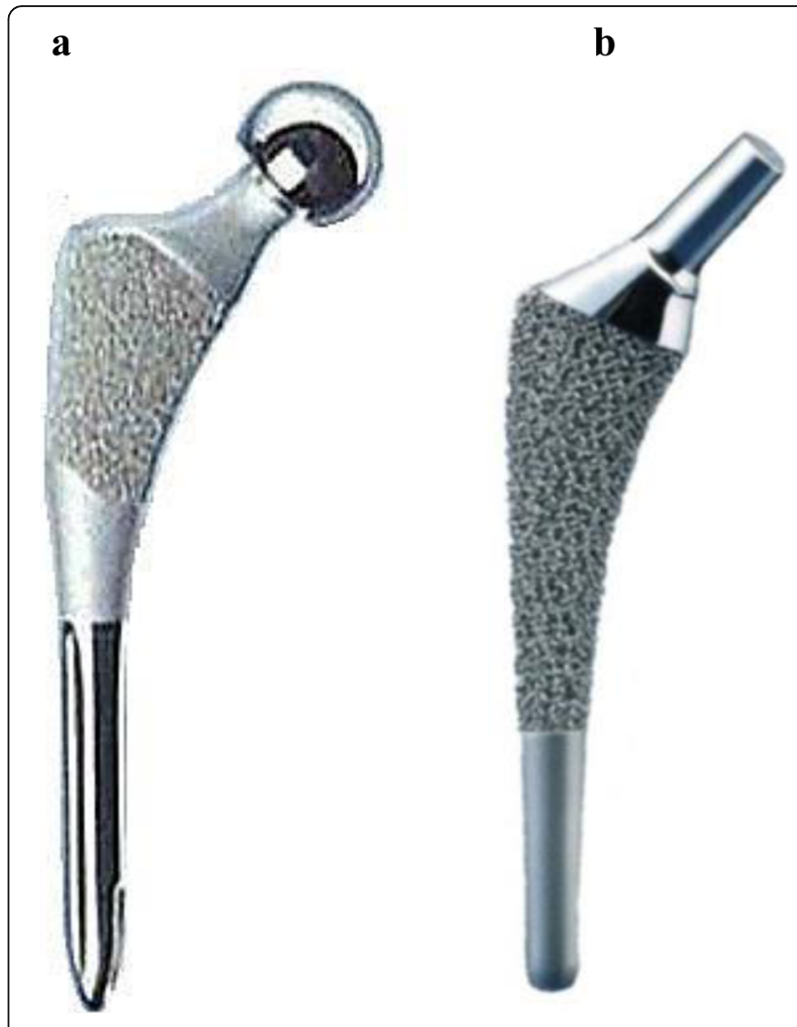

Fig. 1 Cementless femoral stem designs. a Citation; b Spongiosa

Group S, the preoperative diagnosis was OA in 8 hips, osteonecrosis in 10 hips, and rheumatoid arthritis in one hip. There were no differences between Groups $\mathrm{C}$ and $S$ with regard to sex, mean age at surgery, and preoperative diagnosis. Both prostheses were fit-and-fill type with an anatomic stem, and were made of $\mathrm{CoCr}$ alloy. However, porous structure (Citation: beads, Spongiosa: tripod), porous size (Citation: $425 \mu \mathrm{m}$, Spongiosa: $800-1500 \mu \mathrm{m}$ ) and porous area (Citation: proximal $33 \%$ of the stem, Spongiosa: proximal $60 \%$ of the stem) were different.

\section{Radiological evaluation of spot weld sites}

Spot weld sites based on radiographs obtained 5-7 years after surgery were evaluated using Gruen's classification of zones [20] by three orthopedic surgeons. Each zone, except zone IV, was divided into proximal and distal areas. Mean follow-up periods were 66.1 months (range, 60-74 months) and 66.3 months (range, 60-82 months) in Groups $C$ and $S$, respectively. There was no difference between Groups $\mathrm{C}$ and $\mathrm{S}$ with regard to mean follow-up period.

\section{Finite element analysis}

The femur model was created based on a computed tomography (CT) scan of the right femur of a 60-yearold woman diagnosed with OA. Stem models of both 
prostheses were created based on stem samples (Citation: size 2; Spongiosa: size 2, both collarless) that were press-fit into the femur. For more precise expression of the complex three-dimensional forms, a mixture of 8node hexahedral and 6-node pentahedral elements was used. Femur models were created to match both stem shapes. In the analysis of Citation, the femur model contained 1485 8-node hexahedral elements and 8 6-node pentahedral elements, and the stem model contained 7767 8-node hexahedral elements and 114 6-node pentahedral elements. In the analysis of Spongiosa, the femur model contained 1592 8-node hexahedral elements and 7 6-node pentahedral elements, and the stem model contained 68868 -node hexahedral elements and 14 6node pentahedral elements. Young's modulus was set at $394 \mathrm{MPa}$ for the cancellous bone [21], at 17.1 GPa for the femoral cortical bone [22], at $241 \mathrm{GPa}$ for Citation, and at $210 \mathrm{GPa}$ for Spongiosa. Poisson's ratio was set at 0.12 for the cancellous bone and 0.3 for the cortical bone [23] for both prostheses. Regarding the friction coefficients of the interfascial bone surface and prosthesis, the friction coefficient of the porous area was set at 0.3 for Citation and 0.4 for Spongiosa, and the friction coefficient of the nonporous areas was set at 0.1 for both prostheses $[24,25]$. Assuming the task of walking during daily living activities by a patient weighing $50 \mathrm{~kg}$, the loading condition was set based on a study by Heller et al. [26, 27] at resultant forces of $1165 \mathrm{~N}$ (on the stem head), $512 \mathrm{~N}$ (abductor muscle force) and $464 \mathrm{~N}$ (vastus lateralis muscle force) to the grater trochanter. The distal end of the femur was fully fixed and based on radiographic evaluation the following four conditions for the femur-stem bonding sites were set (Fig. 2): (Condition A) no bonding between the femur and stem, assuming initial fixation of the stem; (Condition B) bonding between the femur and stem within the $10 \mathrm{~mm}$ area proximal to the distal border of the stem porous area, taking into account the site for the appearance of spot welds; (Condition $\mathrm{C}$ ) bonding between the femur and entire porous area of the stem; (Condition D) bonding between the femur and the entire area of the stem. We used Marc Mentat 2013.0.0 software (MSC Software Japan, Tokyo, Japan) for the FEA.

\section{Radiological evaluation of stress shielding}

We followed up 27 hips (11 in Group C; 16 in Group S) for approximately $(\sim) 10$ years postoperatively (range, 8 years 7 months- 15 years 3 months). To assess the degree of stress shielding, Engh's classification [28] was used for mid-term radiological evaluation $\sim 5$ years postoperatively (range, 5-6 years 3 months) and long-term evaluation $\sim 10$ years postoperatively. There were no differences between Groups $\mathrm{C}$ and $\mathrm{S}$ with regard to sex, mean age, diagnosis, and mean follow-up period at radiological evaluation of stress shielding.

\section{Evaluation of bone mineral density}

BMD around the each stem and in the each contralateral femur was measured by DEXA (Hologic QDR Discovery W type, Toyo Medic., Tokyo, Japan) at $\sim 10$ years postoperatively. The region of interest was divided into seven Gruen zones. We evaluated the BMD measured by this method in 19 hips (9 in Group C, 10 in Group S) and 11 contralateral hips (6 in Group C, 5 in Group S). Operated hips, a dislocated hip, and a hip with bone atrophy due to paralysis were excluded in the contralateral hips. The mean age at BMD measurement was 66.8 years (range, 48-84 years) in the contralateral hips, 66.3 years (range, 48-80 years) in Group C and 67.1 years (range, 42-84 years) in Group S. There were no differences

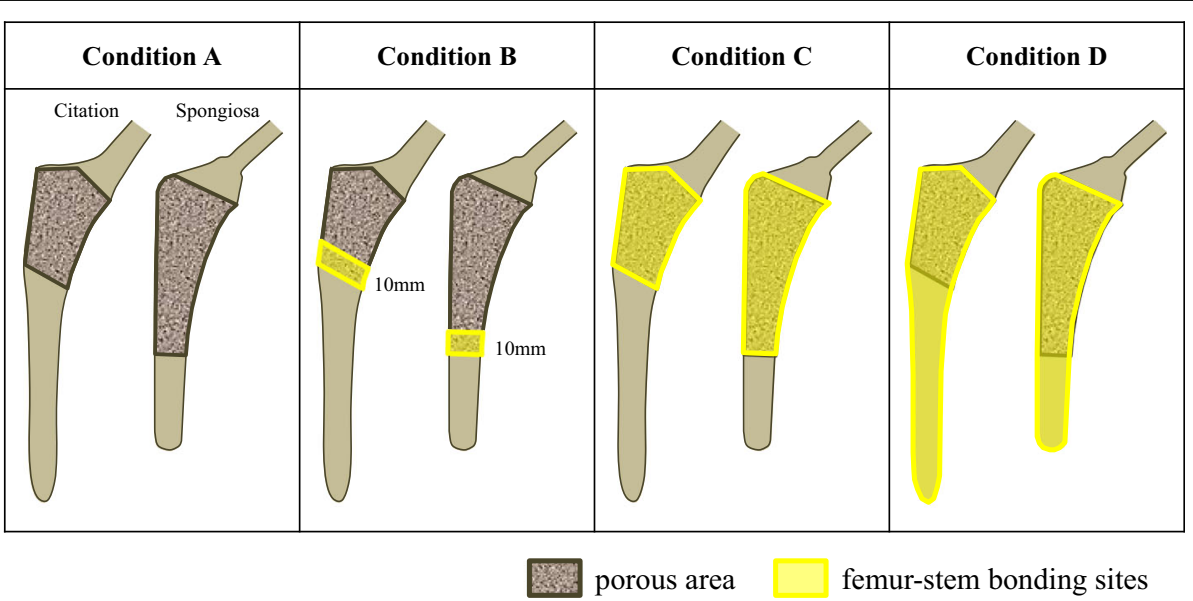

Fig. 2 Four conditions of the femur-stem bonding sites in FEA. Condition A: no bonding between femur and stem; Condition B: bonding between femur and stem within the $10 \mathrm{~mm}$ area proximal to the distal border of the stem porous area; Condition C: bonding between the femur and entire porous area of the stem; Condition D: bonding between the femur and the entire area of the stem 
between Group C, Group S and the contralateral hips with regard to sex, mean age, diagnosis and mean follow-up period at BMD measurement.

\section{Statistical analysis}

The Mann-Whitney $U$ test was used for statistical analysis of the radiological evaluation of stress shielding between Groups C and S. The Tukey-Kramer test was used for statistical analysis of the evaluation of BMD between Group C, Group S and the contralateral hips. Mann-Whitney $U$ test, one-way analysis of variance (ANOVA), and nonparametric Kruskal-Wallis test were used for statistical analysis of sex, mean age, preoperative diagnosis, and mean follow-up period between two groups (Group C and Group S) or three groups (Group $\mathrm{C}$, Group $\mathrm{S}$ and the contralateral hips). The significance level was set at $p<0.05$. Statistical analyses were performed using Statcel3 software (OMS, Saitama, Japan).

\section{Results}

\section{Radiological evaluations of spot weld sites}

Spot welds appeared in zone II proximal (62.5\%), zone VI proximal (43.8 \%), zone I distal (18.8 \%) and zone VII distal (12.5 \%) in Group C (Fig. 3a, Table 1, Additional file 1), and in zone VI distal (73.7 \%), zone II distal (42.1\%), zone V proximal (26.3\%), zone VI proximal (26.3\%), zone III proximal (21.1\%) and zone II proximal (10.5\%) in Group S (Fig. 3b, Table 1, Additional file 1). These data showed that spot welds appeared frequently around the border between the porous and smooth areas in each group. Furthermore, spot welds appeared around the border between the porous and smooth areas in 13 of 16 hips (81.3\%) in Group C and 15 of 19 hips (78.9\%) in Group S.

\section{Finite element analysis}

FEA was used to compare conditions $\mathrm{B}-\mathrm{D}$ with condition A, assuming initial fixation of the stem in each condition. Analysis of the Citation (Fig. 4a) bonded areas found that von Mises stress in condition B was higher than that in condition A. In the area of zone VII, von Mises stress in condition B was lower than that in condition A. In the area of zone I proximal, von Mises stress in condition B was comparable to condition A. In the condition $\mathrm{C}$ bonded areas, (zone I and zone VII), von Mises stress was higher than that in condition A. In the condition D bonded areas (zone I and zone VII, as well as zone II-III and zone V-VI), von Mises stress was higher than that in condition A.

Analysis of the Spongiosa (Fig. 4b) bonded areas found that von Mises stress in condition B was higher than that in condition A. In the areas of zone II proximal, zone VI proximal, and zone VII, von Mises stress in condition $\mathrm{B}$ was lower than that in condition $\mathrm{A}$. In the area of zone I, von Mises stress in condition B was comparable to condition $\mathrm{A}$. In the condition $\mathrm{C}$ bonded areas (zone I-II and zone VI-VII), von Mises stress was higher than that in condition $\mathrm{A}$. In the condition $\mathrm{D}$ bonded areas, (zone I-II and zone VI-VII, as well as

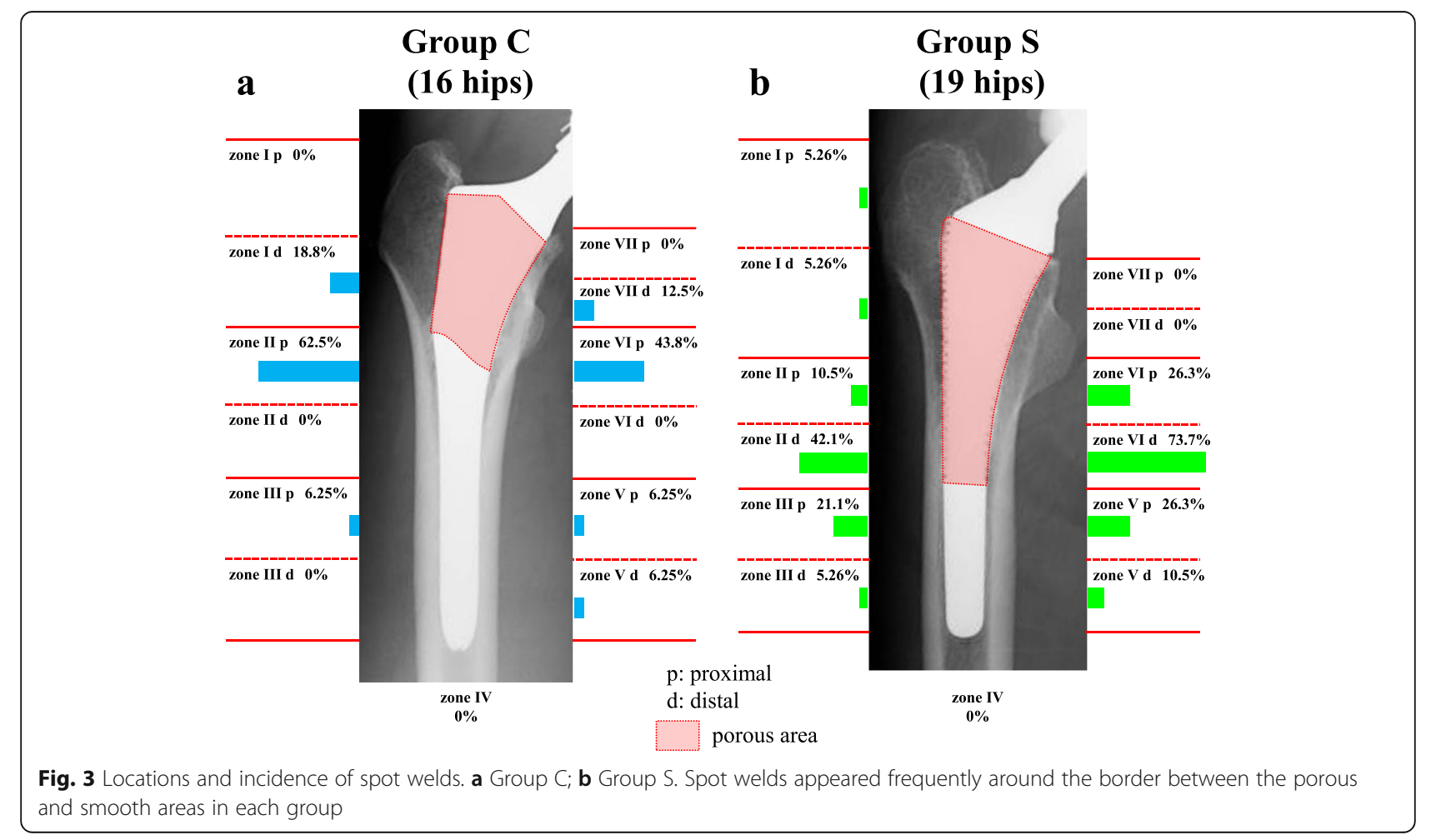


Table 1 Location and incidence of spot welds

\begin{tabular}{llll}
\hline Gruen's zone & & Group C (n=16) & Group S (n=19) \\
\hline zone I & proximal & $0.00 \%(0)$ & $5.26 \%(1)$ \\
& distal & $18.8 \%(3)$ & $5.26 \%(1)$ \\
zone II & proximal & $62.5 \%(10)$ & $10.5 \%(2)$ \\
& distal & $0.00 \%(0)$ & $42.1 \%(8)$ \\
zone III & proximal & $6.25 \%(1)$ & $21.1 \%(4)$ \\
& distal & $0.00 \%(0)$ & $5.26 \%(1)$ \\
zone IV & & $0.00 \%(0)$ & $0.00 \%(0)$ \\
zone V & proximal & $6.25 \%(1)$ & $26.3 \%(5)$ \\
& distal & $6.25 \%(1)$ & $10.5 \%(2)$ \\
zone VI & proximal & $43.8 \%(7)$ & $26.3 \%(5)$ \\
& distal & $0.00 \%(0)$ & $73.7 \%(14)$ \\
zone VII & proximal & $0.00 \%(0)$ & $0.00 \%(0)$ \\
& distal & $12.5 \%(2)$ & $0.00 \%(0)$ \\
\hline
\end{tabular}

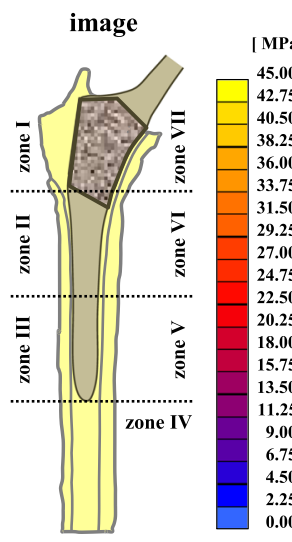

b

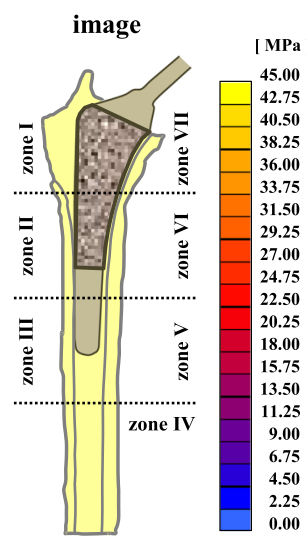

\section{$\mathbf{a}$ \\ Citation}

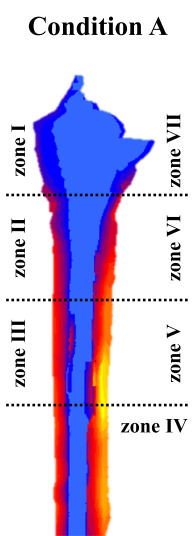

zone III and zone V), von Mises stress was higher than that in condition $\mathrm{A}$.

\section{Radiological evaluation of stress shielding}

In Group $C$, the degree of stress shielding $\sim 5$ years postoperatively was first degree in 9 hips, second degree in 1 hip and third degree 1 hip. At 10 years postoperatively, stress shielding was classified as first degree in 4 hips, second degree in 6 hips, and third degree in 1 hip (Fig. 5a, Table 2, Additional file 2). In Group S, the degree of stress shielding at $\sim 5$ years postoperatively was no stress shielding in 1 hip, first degree in 10 hips, second degree in 4 hips, and third degree in 1 hip. At $\sim 10$ years postoperatively, stress shielding was no stress shielding in 1 hip, first degree in 3 hips, second degree in 10 hips, and third degree in 2 hips (Fig. 5b, Table 3, Additional file 2).

Stress shielding progressed in 5 of 11 hips (45.5\%, 5 hips: from first to second degree) in Group $\mathrm{C}$ and in 8 of 16 hips (50.0 \%, 7 hips: from first to second degree; one hip: from second to third degree) in Group $\mathrm{S}$ from 5
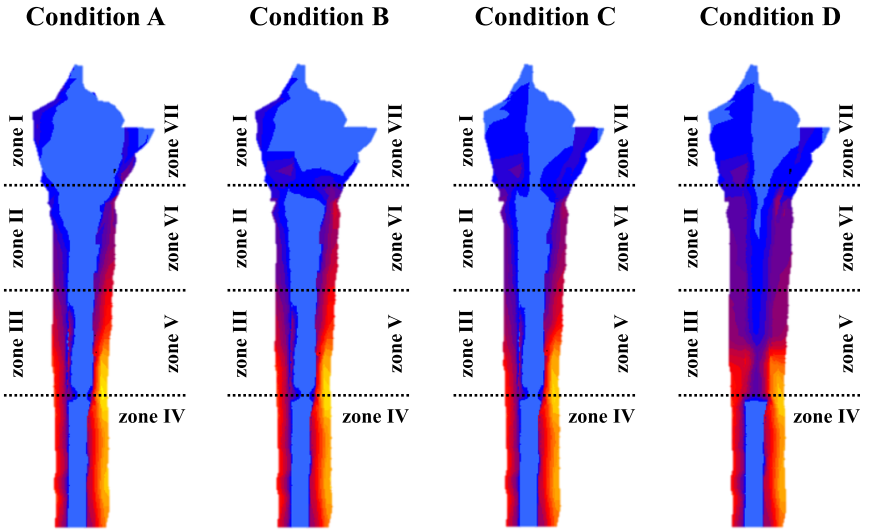

Spongiosa
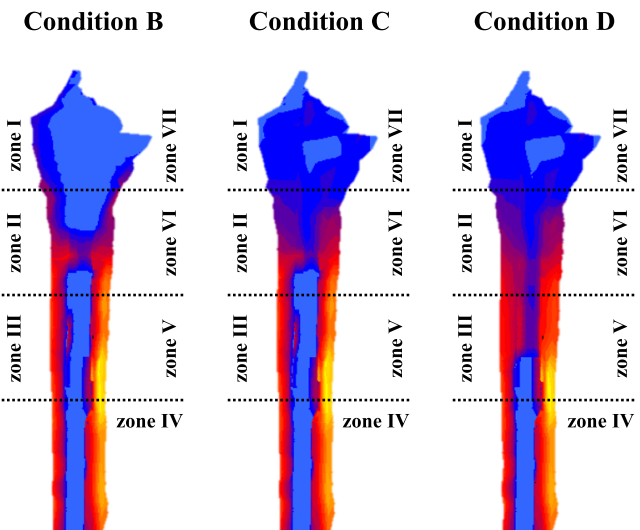

Fig. 4 von Mises stress distribution at coronal section of the femur. a Citation; b Spongiosa 

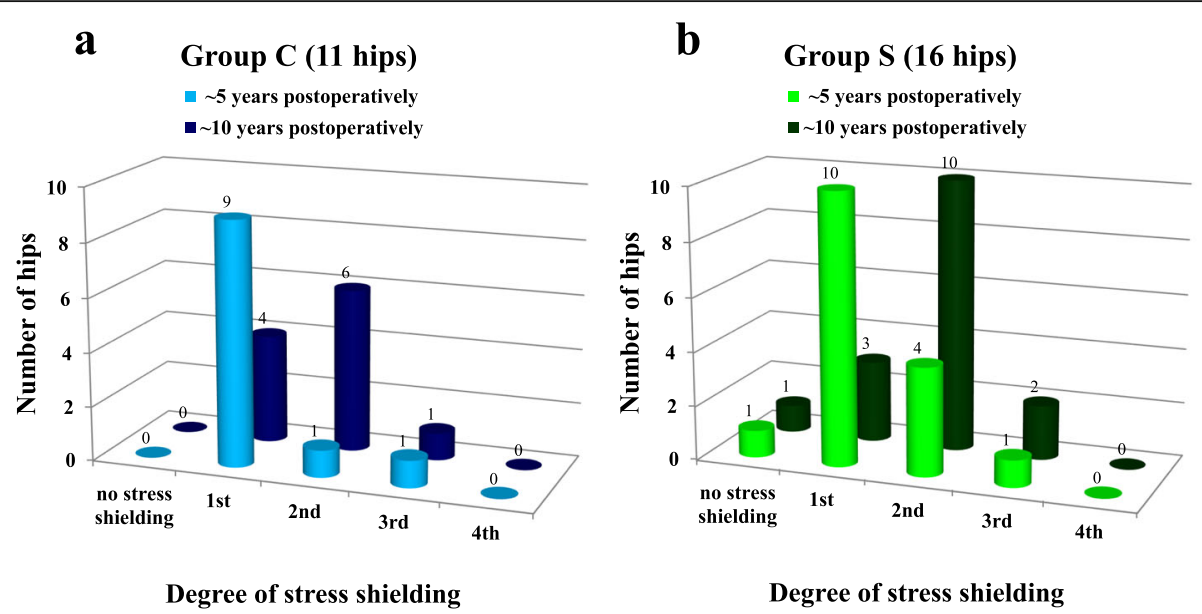

Fig. 5 Comparison of stress shielding $\sim 5$ and $\sim 10$ years postoperatively. a Group C; b Group S. Stress shielding $\sim 10$ years postoperatively was intensified in $\sim 50 \%$ of hips in both groups compared with that $\sim 5$ years postoperatively

to 10 years postoperatively. At final observation, seconddegree or greater stress shielding occurred in 7 of 11 hips (63.6 \%) in Group C, and 12 of 16 hips (75.0 \%) in Group S (Table 4, Additional file 3). There were no significant differences between Groups C and S with regard to the progression of stress shielding and the case of second-degree or greater stress shielding at final observation.

Because there were no significant differences between Groups $C$ and $S$ with regard to these findings, all 27 hips were assessed for the presence or absence of spot welds around the border between the porous and smooth areas and were compared for stress shielding (Table 5, Additional file 3). Stress shielding progressed in 12 of 21 hips $(57.1 \%)$ in which spot welds were present and in 1 of 6 hips $(16.7 \%)$ in which spot welds were absent. Stress shielding tended to progress in the presence rather than absence of spot welds, but the difference was not significant $(p=0.086)$. Second-degree or greater stress shielding was significantly greater in the presence (18 of 21 hips, $85.7 \%$ ) compared with absence (1 of 6 hips, $16.7 \%)$ of spot welds at final observation $(p<0.01)$.

\section{Evaluation of bone mineral density}

In zone VII, mean BMDs in Groups $\mathrm{C}$ and $\mathrm{S}$ were significantly lower than those in the contralateral hips

Table 2 In Group C, comparison of stress shielding $\sim 5$ and $\sim 10$ years postoperatively

\begin{tabular}{lll}
\hline $\begin{array}{l}\text { The degree of stress } \\
\text { shielding }\end{array}$ & $\begin{array}{l}\sim 5 \text { years } \\
\text { postoperatively }\end{array}$ & $\sim$ 10 years \\
\hline no stress shielding & 0 & 0 \\
1st & 9 & 4 \\
2nd & 1 & 6 \\
3rd & 1 & 1 \\
4th & 0 & 0 \\
\hline
\end{tabular}

$(p<0.01)$. Furthermore, in zone II, the mean BMD in Group $\mathrm{S}$ was significantly lower than that in Group C $(p<0.05)$. In all other zones, there were no significant differences in mean BMDs between Groups $C$ and $S$ and the contralateral hips (Fig. 6, Table 6, Additional file 4).

\section{Discussion}

The stability and durability of cementless femoral stems after THA are affected by periprosthetic bone remodeling. We radiologically determined the femur-stem bonding sites according to the location of spot welds in two designs of cementless stem and performed FEA in different bonding conditions. Furthermore, we examined the progression of stress shielding and BMD as a result.

Spot welds appeared most frequently around the border between the porous area and the smooth area in each group. We therefore postulated that the femurstem bonding sites occurred within the area $10 \mathrm{~mm}$ proximal to the distal border of the stem's porous area. FEA showed that von Mises stress under condition B, based on mid-term radiological evaluation, was reduced in the area proximal to the femur-stem bonding sites for both prostheses compared with that under condition A (no bonding). Conversely, von Mises stress in all areas of femur-stem bonding sites in conditions $\mathrm{C}$ and $\mathrm{D}$ was

Table 3 In Group S, comparison of stress shielding $\sim 5$ and $\sim 10$ years postoperatively

\begin{tabular}{|c|c|c|}
\hline $\begin{array}{l}\text { The degree of stress } \\
\text { shielding }\end{array}$ & $\begin{array}{l}\sim 5 \text { years } \\
\text { postoperatively }\end{array}$ & $\begin{array}{l}\sim 10 \text { years } \\
\text { postoperatively }\end{array}$ \\
\hline no stress shielding & 1 & 1 \\
\hline 1 st & 10 & 3 \\
\hline 2nd & 4 & 10 \\
\hline $3 r d$ & 1 & 2 \\
\hline 4th & 0 & 0 \\
\hline
\end{tabular}


Table 4 Comparison of stress shielding between Groups $C$ and $S$

\begin{tabular}{|c|c|c|c|}
\hline & Group C & Group S & $P$ value \\
\hline Total number of hips & 11 & 16 & \\
\hline Progression of stress shielding (ratio) $)^{a}$ & $5(45.5 \%)$ & $8(50 \%)$ & 0.820 \\
\hline Stress shielding $\geq 2$ nd degree (ratio $)^{b}$ & $7(63.6 \%)$ & $12(75.0 \%)$ & 0.533 \\
\hline
\end{tabular}

higher than that in condition A. These findings suggest that the stress shielding in condition $B$ may be more intensified than that in conditions $\mathrm{C}$ or D.

We then investigated whether FEA under condition $B$, based on mid-term radiological evaluation, could determine the outcome 10 years after THA. With respect to the progression of stress shielding from 5 to 10 years after THA, there was no significant difference between the two stem designs. In addition, there was no significant difference in the degree of stress shielding between the two stem designs. Engh's classification of stress shielding provides a rough evaluation, therefore the Group C versus Group S evaluation of stress shielding may not be sufficiently accurate [29]. However, stress shielding progressed and was significantly higher in the presence of spot welds around the border between the porous and smooth areas. These results were congruous to the FEA of condition B under which von Mises stress was reduced in the area proximal to femur-stem bonding sites.

In both stem designs, BMD in zone VII was significantly lower than that in the contralateral hip. FEA showed that stress shielding at zone VII was increased in conditions $\mathrm{C}$ and $\mathrm{D}$ compared with condition $\mathrm{A}$, but was decreased compared with condition $B$. Therefore, condition $\mathrm{B}$ may be more appropriate than conditions $\mathrm{C}$ or $\mathrm{D}$ for predicting stress shielding. In addition, BMD in zone II was significantly lower in Group S than that in Group C. It is possible that stress shielding was more intensified in Group S than in Group C, particularly in zone II. These findings substantiated that the stem-femur fixation site in Group S was more distal than in Group C.

Regardless of bonding condition, von Mises stress was increased at the distal site of the cementless stems, and

Table 5 Comparison of stress shielding between cases of the presence and absence of spot welds

\begin{tabular}{llll}
\hline & $\begin{array}{l}\text { Presence of } \\
\text { spot welds }\end{array}$ & $\begin{array}{l}\text { Absence of } \\
\text { spot welds }\end{array}$ & $P$ value \\
\hline Total number of hips & 21 & 6 & \\
$\begin{array}{l}\text { Progression of stress } \\
\text { shielding (ratio) }\end{array}$ & $12(57.1 \%)$ & $1(16.7 \%)$ & 0.086 \\
$\begin{array}{l}\text { Stress shielding } \geq 2 \text { nd } \\
\text { degree (ratio) }\end{array}$ & $18(85.7 \%)$ & $1(16.7 \%)$ & 0.001 \\
\hline
\end{tabular}

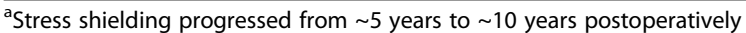

${ }^{\mathrm{b}}$ Second-degree or greater stress shielding at $\sim 10$ years postoperatively decreased proximally. Changes in stress distribution depend on stem stiffness, and stress shielding is known to influence current cementless stems [16, 30, 31]. Furthermore, the extent of stress shielding is affected by the bonding conditions of the implant-bone interface [32].

To reduce stress shielding, proximal femur-stem bonding is preferable to distal femur-stem bonding. Therefore, modification of the stem design has been attempted to reduce the porous coating area [33-35]. However, decreasing the extent of the porous coating alone does not necessarily reduce proximal femoral bone loss [36].

Femur-stem bonding was not identified in all porous areas. Spot welds, indicating bone ingrowth to the implant interface, were mainly located at the distal site of the porous area, not only in extensively-coated cases, but also in proximally-coated cases [36]. Interestingly, grid blasting onto the distal prosthesis part is known to result in bone remodeling at the boundary of the distal grid blasted and polished areas (zones 3 and 5), as well as at the proximal porous-coated area [37, 38].

Of the two stem designs assessed, the differences in their porous structures and coated surface areas did not significantly affect progression of stress shielding from 5 to 10 years. However, the presence or absence of spot welds did affect progression of long-term stress shielding. These findings indicate that stress shielding is affected by the bonding conditions of the implant-bone interface.

Measurement of BMD can evaluate the impact of stress shielding [39]. In the present study, the only significant difference between the two stem designs, owing to the different porous areas, was in zone II 10 years postoperatively. Because porous structure was different from Citation in Spongiosa, we set the different friction coefficient for each stems in FEA. The change of the von Mises stress by the difference in the friction coefficient might modify the influence of the different range of porous area, therefore it was difficult to predict the difference of BMD results in the two stem designs by FEA. Setting the same friction coefficient in FEA or comparing in the same porous designs may be needed to predict the differences of BMD influenced by range of porous area using FEA.

Our results suggested that not only was the initial stem-cortical bone contact area affected by stem design, but also the later stem-femur bonding area due to bone ingrowth, both of which should be taken into account when predicting the long-term outcome of cementless stems.

Spot welds were not always observed following THA, and their locations varied between individual cases. Preoperative $\mathrm{BMD}$ is one major factor that influences periprosthetic bone loss [40]. Post-operative bone loss was 


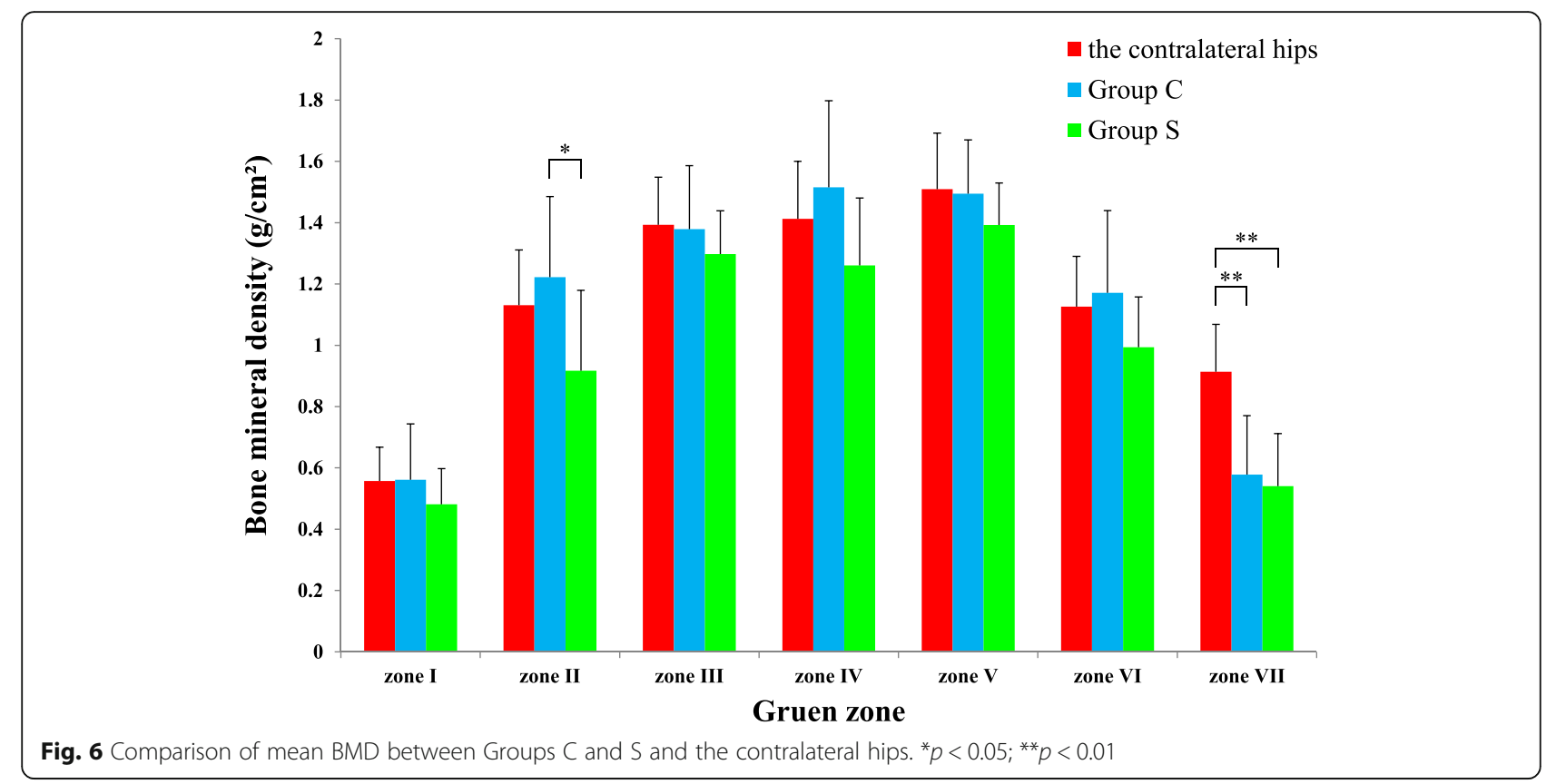

also observed in the late phase 5 years or more after surgery [37].

Preoperative factors that influence postoperative bone remodeling around the stem include prosthetic-related (materials [41-44], shape [45, 46], size [47-50], extent of porous area $[35,41,47,48])$ and patient-related (BMD $[40,49,51,52]$, sex $[53,54]$, bone canal shape [55-57]). These preoperative factors may not be sufficient to predict long-term radiological outcomes. It is therefore essential to evaluate bone remodeling around the stem several years after operation and to use these findings to determine FEA conditions. Taken together, our results indicate that FEA based on mid-term radiological evaluation, may be helpful to predict the influence of longterm stress shielding more precisely.

Although the present study verified FEA could be used to evaluate changes in the stem-femur bonding conditions, it could not be used to directly compare Citation and Spongiosa. Consequently, the effects of porous area should be verified using the same stem design. Several limitations exist in this study. First, BMD was not measured over time, therefore we could not exactly define bone loss from preoperative bone quality. Second, we used a representative femoral bone model obtained from one CT database case. Consequently, the defined stemfemur bonding sites based on spot welds are not necessarily consistent with the radiological findings of all patients. To predict personal outcomes in individual cases, FEA modified by individual personal data would be needed.

\section{Conclusions}

Our results suggest that not only was the initial stemcortical bone contact area affected by stem design but also by the later stem-femur bonding area due to bone ingrowth, both of which should be taken into account to predict long-term outcomes of cementless stems. FEA based on mid-term radiological evaluation may be helpful to predict the influence of long-term stress shielding more precisely.

Table 6 Comparison of mean BMD between Groups $C$ and S and the contralateral hips

\begin{tabular}{|c|c|c|c|c|c|c|c|c|}
\hline & & \multicolumn{7}{|c|}{ Gruen zone } \\
\hline & & I & $\|$ & III & IV & V & $\mathrm{Vl}$ & $\mathrm{VII}$ \\
\hline \multirow[t]{2}{*}{ The contralateral hips } & average $(\mathrm{g} / \mathrm{cm} 2)$ & 0.557 & 1.131 & 1.393 & 1.412 & 1.509 & 1.126 & 0.913 \\
\hline & SD & 0.110 & 0.180 & 0.155 & 0.188 & 0.183 & 0.165 & 0.155 \\
\hline \multirow[t]{2}{*}{ Group C } & average (g/cm2) & 0.561 & 1.222 & 1.379 & 1.516 & 1.495 & 1.171 & 0.578 \\
\hline & SD & 0.183 & 0.263 & 0.207 & 0.282 & 0.176 & 0.269 & 0.193 \\
\hline \multirow[t]{2}{*}{ Group S } & average (g/cm2) & 0.481 & 0.917 & 1.298 & 1.261 & 1.393 & 0.994 & 0.541 \\
\hline & SD & 0.117 & 0.262 & 0.141 & 0.219 & 0.137 & 0.164 & 0.171 \\
\hline
\end{tabular}




\section{Additional files}

Additional file 1: Locations and incidence of spot welds (Fig. 3). (XLSX $10 \mathrm{~kb}$ )

Additional file 2: Comparison of stress shielding $\sim 5$ and $\sim 10$ years postoperatively (Fig. 5). (XLSX 12 kb)

Additional file 3: Comparison of stress shielding (Tables 4 and 5). (XLSX $10 \mathrm{~kb}$ )

Additional file 4: Comparison of mean BMD between Groups $C$ and S and the contralateral hips (Fig. 6). (XLSX 13 kb)

\section{Abbreviations}

BMD: Bone mineral density; CT: Computed tomography; DEXA: Dual energy X-ray absorptiometry; FEA: Finite element analysis; OA: Osteoarthritis; THA: Total hip arthroplasty

\section{Acknowledgements}

The authors would like to thank Mrs. Akemi Godai for her invaluable assistance.

\section{Availability of data and materials}

The datasets supporting the conclusions of this article are included within the article and its additional files.

\section{Authors' contributions}

KM and YI conceived and designed the study. KM, YMG, HK, TS, SN, and IK collected the data. YI, YMG, SM and SK analyzed the data. YI and SK wrote the manuscript. All authors read and approved the final manuscript.

\section{Competing interests}

The authors declare that they have no competing interests.

\section{Consent for publication}

Not applicable.

\section{Ethics approval and consent to participate}

This research protocol was approved by the Ethics Committee on Clinical Research at Kagoshima University Hospital (No. 27-55). All data were retrospectively collected from medical records. All patients gave their informed consent for participation in this clinical study.

\section{Author details}

1 Department of Medical Joint Materials, Graduate School of Medical and Dental Science, Kagoshima University, 8-35-1 Sakuragaoka, Kagoshima 890-8520, Japan. ²Department of Mechanical Engineering, Graduate School of Science and Engineering, Kagoshima University, Kagoshima, Japan. ${ }^{3}$ Department of Orthopaedic Surgery, Graduate School of Medical and Dental Science, Kagoshima University, Kagoshima, Japan. ${ }^{4}$ The Near-Future Locomotor Organ Medicine Creation Course (Kusunoki Kai), Graduate School of Medical and Dental Science, Kagoshima University, Kagoshima, Japan.

Received: 19 April 2016 Accepted: 15 September 2016

Published online: 19 September 2016

\section{References}

1. Capello WN, D'Antonio JA, Jaffe WL, Geesink RG, Manley MT, Feinberg JR. Hydroxyapatite-coated femoral components: 15-year minimum followup. Clin Orthop Relat Res. 2006;453:75-80.

2. Epinette JA, Manley MT. Uncemented stems in hip replacementhydroxyapatite or plain porous: does it matter? Based on a prospective study of HA Omnifit stems at 15-years minimum follow-up. Hip Int. 2008; 18(2):69-74.

3. Goosen JH, Kums AJ, Kollen BJ, Verheyen CC. Porous-coated femoral components with or without hydroxyapatite in primary uncemented total hip arthroplasty: a systematic review of randomized controlled trials. Arch Orthop Trauma Surg. 2009:129(9):1165-9.

4. Yamada H, Yoshihara Y, Henmi O, Morita M, Shiromoto Y, Kawano T, et al. Cementless total hip replacement: past, present, and future. J Orthop Sci. 2009;14:228-41.
5. Khanuja HS, Vakil JJ, Goddard MS, Mont MA. Cementless femoral fixation in total hip arthroplasty. J Bone Joint Surg Am. 2011:93(5):500-9.

6. Huiskes R, Weinans H, Grootenboer HJ, Dalstra M, Fudala B, Slooff TJ. Adaptive bone-remodeling theory applied to prosthetic-design analysis. J Biomech. 1987;20(11-12):1135-50.

7. Sumner DR. Long-term implant fixation and stress-shielding in total hip replacement. J Biomech. 2015;48(5):797-800.

8. Wilkinson JM, Hamer AJ, Rogers A, Stockley I, Eastell R. Bone mineral density and biochemical markers of bone turnover in aseptic loosening after total hip arthroplasty. J Orthop Res. 2003;21(4):691-6.

9. Rosenbaum Chou TG, Child JR, Naughtin RJ, Rigdon RR, Schumann C, Bloebaum RD. The relationship between femoral periprosthetic cortical bone geometry and porosity after total hip arthroplasty. J Biomed Mater Res A. 2008;87(1):107-15.

10. Engh Jr CA, Young AM, Engh Sr CA, Hopper Jr RH. Clinical consequences of stress shielding after porous-coated total hip arthroplasty. Clin Orthop Relat Res. 2003;417:157-63.

11. Watanabe $Y$, Shiba N, Matsuo S, Higuchi F, Tagawa Y, Inoue A. Biomechanical study of the resurfacing hip arthroplasty: finite element analysis of the femoral component. J Arthroplasty. 2000;15(4):505-11.

12. Abdul-Kadir MR, Hansen U, Klabunde R, Lucas D, Amis A. Finite element modelling of primary hip stem stability: the effect of interference fit. J Biomech. 2008:41:587-94.

13. Ong KL, Day JS, Manley MT, Kurtz SM, Geesink R. Biomechanical comparison of 2 proximally coated femoral stems: effects of stem length and surface finish. J Arthroplasty. 2009;24(5):819-24.

14. Hirata Y, Inaba Y, Kobayashi N, Ike H, Fujimaki H, Saito T. Comparison of mechanical stress and change in bone mineral density between two types of femoral implant using finite element analysis. J Arthroplasty. 2013;28(10):1731-5.

15. ten Broeke RH, Tarala M, Arts JJ, Janssen DW, Verdonschot N, Geesink RG. Improving peri-prosthetic bone adaptation around cementless hip stems: a clinical and finite element study. Med Eng Phys. 2014:36(3):345-53.

16. Kerner J, Huiskes $R$, van Lenthe $G H$, Weinans $H$, van Rietbergen $B$, Engh CA, et al. Correlation between pre-operative periprosthetic bone density and post-operative bone loss in THA can be explained by strain-adaptive remodelling. J Biomech. 1999;32(7):695-703.

17. Scannell PT, Prendergast PJ. Cortical and interfacial bone changes around a non-cemented hip implant: simulations using a combined strain/damage remodelling algorithm. Med Eng Phys. 2009;31(4):477-88.

18. Turner AW, Gillies RM, Sekel R, Morris P, Bruce W, Walsh WR. Computational bone remodelling simulations and comparisons with DEXA results. J Orthop Res. 2005:23(4):705-12.

19. Engh CA, Massin P, Suthers KE. Roentgenographic assessment of the biologic fixation of porous-surfaced femoral components. Clin Orthop Relat Res. 1990:257:107-28.

20. Gruen TA, McNeice GM, Amstutz HC. "Modes of failure" of cemented stemtype femoral components: a radiographic analysis of loosening. Clin Orthop Relat Res. 1979;141:17-27.

21. Hobatho MC, Rho JY, Ashman RB. Anatomical variation of human cancellous bone mechanical properties in vitro. Stud Health Technol Inform 1997:40:157-73.

22. Burstein AH, Reilly DT, Martens M. Aging of bone tissue: mechanical properties. J Bone Joint Surg Am. 1976:58(1):82-6.

23. Wirtz DC, Schiffers N, Pandorf T, Radermacher K, Weichert D, Forst R. Critical evaluation of known bone material properties to realize anisotropic FEsimulation of the proximal femur. J Biomech. 2000;33(10):1325-30.

24. Pettersen SH, Wik TS, Skallerud B. Subject specific finite element analysis of implant stability for a cementless femoral stem. Clin Biomech (Bristol, Avon). 2009;24(6):480-7.

25. Spears IR, Morlock MM, Pfleiderer M, Schneider E, Hille E. The influence of friction and interference on the seating of a hemispherical press-fit cup: a finite element investigation. J Biomech. 1999:32(11):1183-9.

26. Heller MO, Bergmann G, Deuretzbacher G, Dürselen L, Pohl M, Claes L, et al. Musculo-skeletal loading conditions at the hip during walking and stair climbing. J Biomech. 2001;34(7):883-93.

27. Heller MO, Bergmann G, Kassi JP, Claes L, Haas NP, Duda GN. Determination of muscle loading at the hip joint for use in pre-clinical testing. J Biomech. 2005:38(5):1155-63.

28. Engh CA, Bobyn JD, Glassman AH. Porous-coated hip replacement. The factors governing bone ingrowth, stress shielding, and clinical results. J Bone Joint Surg (Br). 1987;69(1):45-55. 
29. Engh Jr CA, McAuley JP, Sychterz CJ, Sacco ME, Engh Sr CA. The accuracy and reproducibility of radiographic assessment of stress-shielding. A postmortem analysis. J Bone Joint Surg Am. 2000;82-A(10):1414-20.

30. Van Rietbergen B, Huiskes R, Weinans H, Sumner DR, Turner TM, Galante JO. ESB Research Award 1992. The mechanism of bone remodeling and resorption around press-fitted THA stems. J Biomech. 1993;26(4-5):369-82.

31. Huiskes R, Weinans $H$, Dalstra M. Adaptive bone remodeling and biomechanical design considerations for noncemented total hip arthroplasty. Orthopedics. 1989;12(9):1255-67.

32. Huiskes R. The various stress patterns of press-fit, ingrown, and cemented femoral stems. Clin Orthop Relat Res. 1990;261:27-38.

33. Weinans H, Huiskes R, Grootenboer HJ. Effects of fit and bonding characteristics of femoral stems on adaptive bone remodeling. J Biomech Eng. 1994;116(4):393-400.

34. Skinner HB, Kim AS, Keyak JH, Mote Jr CD. Femoral prosthesis implantation induces changes in bone stress that depend on the extent of porous coating. J Orthop Res. 1994;12(4):553-63.

35. Yamaguchi K, Masuhara K, Ohzono K, Sugano N, Nishii T, Ochi T. Evaluation of periprosthetic bone-remodeling after cementless total hip arthroplasty. The influence of the extent of porous coating. J Bone Joint Surg Am. 2000; 82-A(10):1426-31.

36. McAuley JP, Sychterz CJ, Engh Sr CA. Influence of porous coating level on proximal femoral remodeling. A postmortem analysis. Clin Orthop Relat Res. 2000;371:146-53.

37. Nishino T, Mishima H, Kawamura H, Shimizu Y, Miyakawa S, Ochiai N. Follow-up results of 10-12 years after total hip arthroplasty using cementless tapered stem - frequency of severe stress shielding with synergy stem in Japanese patients. J Arthroplasty. 2013;28(10):1736-40.

38. Danesh-Clough T, Bourne RB, Rorabeck CH, McCalden R. The mid-term results of a dual offset uncemented stem for total hip arthroplasty. J Arthroplasty. 2007;22(2):195-203.

39. Smart RC, Barbagallo S, Slater GL, Kuo RS, Butler SP, Drummond RP, Sekel R. Measurement of periprosthetic bone density in hip arthroplasty using dualenergy x-ray absorptiometry. Reproducibility of measurements. J Arthroplasty. 1996;11(4):445-52.

40. Rahmy Al, Gosens T, Blake GM, Tonino A, Fogelman I. Periprosthetic bone remodelling of two types of uncemented femoral implant with proximal hydroxyapatite coating: a 3-year follow-up study addressing the influence of prosthesis design and preoperative bone density on periprosthetic bone loss. Osteoporos Int. 2004;15(4):281-9.

41. Bobyn JD, Mortimer ES, Glassman AH, Engh CA, Miller JE, Brooks CE. Producing and avoiding stress shielding. Laboratory and clinical observations of noncemented total hip arthroplasty. Clin Orthop Relat Res. 1992;274:79-96.

42. Sumner DR, Turner TM, Urban RM, Galante JO. Experimental studies of bone remodeling in total hip arthroplasty. Clin Orthop Relat Res. 1992;276:83-90

43. Kärrholm J, Anderberg C, Snorrason F, Thanner J, Langeland N, Malchau H, Herberts P. Evaluation of a femoral stem with reduced stiffness. A randomized study with use of radiostereometry and bone densitometry. J Bone Joint Surg Am. 2002;84-A(9):1651-8.

44. Kim YH. Titanium and cobalt-chrome cementless femoral stems of identical shape produce equal results. Clin Orthop Relat Res. 2004;427:148-56.

45. Sano K, Ito K, Yamamoto K. Changes of bone mineral density after cementless total hip arthroplasty with two different stems. Int Orthop. 2008; 32(2):167-72.

46. Albanese CV, Santori FS, Pavan L, Learmonth ID, Passariello R, DXA. Periprosthetic DXA after total hip arthroplasty with short vs. ultra-short custom-made femoral stems: 37 patients followed for 3 years. Acta Orthop. 2009;80(3):291-7.

47. Engh CA, Bobyn JD. The influence of stem size and extent of porous coating on femoral bone resorption after primary cementless hip arthroplasty. Clin Orthop Relat Res. 1988;231:7-28.

48. Kilgus DJ, Shimaoka EE, Tipton JS, Eberle RW. Dual-energy X-ray absorptiometry measurement of bone mineral density around porouscoated cementless femoral implants. Methods and preliminary results. J Bone Joint Surg (Br). 1993;75(2):279-87.

49. Nishii T, Sugano N, Masuhara K, Shibuya T, Ochi T, Tamura S. Longitudinal evaluation of time related bone remodeling after cementless total hip arthroplasty. Clin Orthop Relat Res. 1997;339:121-31.

50. Sköldenberg OG, Bodén HS, Salemyr MO, Ahl TE, Adolphson PY Periprosthetic proximal bone loss after uncemented hip arthroplasty is related to stem size: DXA measurements in 138 patients followed for 2-7 years. Acta Orthop. 2006;77(3):386-92.

51. Engh CA, McGovern TF, Schmidt LM. Roentgenographic densitometry of bone adjacent to a femoral prosthesis. Clin Orthop Relat Res. 1993;292:177-90.

52. Venesmaa PK, Kröger HP, Miettinen HJ, Jurvelin JS, Suomalainen OT, Alhava EM. Monitoring of periprosthetic BMD after uncemented total hip arthroplasty with dual-energy X-ray absorptiometry-a 3-year follow-up study. J Bone Miner Res. 2001;16(6):1056-61.

53. Sychterz CJ, Engh CA. The influence of clinical factors on periprosthetic bone remodeling. Clin Orthop Relat Res. 1996;322:285-92.

54. Merle C, Streit MR, Volz C, Pritsch M, Gotterbarm T, Aldinger PR. Bone remodeling around stable uncemented titanium stems during the second decade after total hip arthroplasty: a DXA study at 12 and 17 years. Osteoporos Int. 2011;22(11):2879-86.

55. Cooper HJ, Jacob AP, Rodriguez JA. Distal fixation of proximally coated tapered stems may predispose to a failure of osteointegration. J Arthroplasty. 2011;26(6 Suppl):78-83.

56. Aro HT, Alm JJ, Moritz N, Mäkinen TJ, Lankinen P. Low BMD affects initial stability and delays stem osseointegration in cementless total hip arthroplasty in women: a 2-year RSA study of 39 patients. Acta Orthop. 2012:83(2):107-14.

57. Issa K, Stroh AD, Mont MA, Bonutti PM. Effect of bone type on clinical and radiographic outcomes of a proximally-coated cementless stem in primary total hip arthroplasties. J Orthop Res. 2014;32(9):1214-20.

\section{Submit your next manuscript to BioMed Central and we will help you at every step:}

- We accept pre-submission inquiries

- Our selector tool helps you to find the most relevant journal

- We provide round the clock customer support

- Convenient online submission

- Thorough peer review

- Inclusion in PubMed and all major indexing services

- Maximum visibility for your research

Submit your manuscript at www.biomedcentral.com/submit
) Biomed Central 